NOTICIAS Y COMENTARIOS 


\title{
INCIDENCIAS DE LA VARIABILIDAD TÉRMICA Y LOS TIPOS DE CIRCULACIÓN ATMOSFÉRICA SOBRE EL NÚMERO DE CASOS Y LA TASA DE GRIPE EN LA CIUDAD DE VITORIA: UNOS RESULTADOS PARA LA REFLEXIÓN
}

\author{
Pablo Fernández de Arróyabe Hernáez \\ Servicio Vasco de Meteorología
}

\begin{abstract}
RESUMEN
El presente artículo se sitúa conceptualmente dentro del área de la climatología médica. Trata acerca de la relación existente entre la variabilidad de alta frecuencia experimentada por la temperatura en la ciudad de Vitoria, las situaciones sinópticas diarias y el número de diagnósticos de gripe registrados por la Red de Médicos Vigía de la Comunidad Autónoma del País Vasco en mencionada localidad. Los resultados obtenidos en este estudio preliminar muestran la existencia de una importante conexión entre los tres factores durante el periodo de expansión de la enfermedad en la ciudad de Vitoria en el otoño - invierno de 1999. Finalmente, se incide en la importancia que esta relación puede tener en el área de la planificación sanitaria de cara a la implantación de métodos de análisis preventivos que faciliten la gestión de los recursos sanitarios en fases expansivas de epidemias gripales.
\end{abstract}

Palabras clave: Semana epidemiológica, red de médicos vigía, variabilidad, tasa de gripe, situación sinóptica.

\begin{abstract}
This article can be enclosured in the medical climatology area. It deals about the relation that has been found between the high frecuency temperature variability in the city of Vitoria (Spain), the atmosferic circulation patterns and the number of flu diagnostics that have been registered by the Basque Health Service in the last winter period in that city. According to the preliminary results can be established that this relation could be applied to the health services planning or, at least, they shoul be consired in order to avoid queuing in the emergency centers in the flu expansion period.
\end{abstract}

Key words: Epidemiologic period, medical sentinel network, variability, flu rate, circulation types. 


\section{Introducción. La gripe y la temperatura}

La gripe, o influenza, es una infección respiratoria causada por virus cuya peculiaridad radica en su falta de estabilidad. Muta fácilmente con lo que su tratamiento se complica. La gripe es una enfermedad común que se transmite de unas personas a otras a través de las membranas mucosas en la boca, en la nariz u ojos. Se trata de una enfermedad muy contagiosa y la podemos padecer durante unos pocos días o a lo largo de varias semanas.

Generalmente sucede que la gripe ataca nuestro organismo entre uno y tres días después de que hayamos contraído el virus. Es entonces, cuando recurrimos a remedios «caseros» que nos permitan solucionar la infección sin tener que acudir al médico. Será unos días más tarde, si los remedios tradicionales han fracasado, cuando nos vemos obligados a visitar el ambulatorio con el fin de obtener ayuda por parte del profesional médico correspondiente.

Los casos de gripe suelen ser más frecuentes en las estaciones de otoño e invierno que en los trimestres de primavera o verano. Ante síntomas parecidos, en época de Primavera o Verano, solemos hablar de catarro o constipado. Por lo tanto, estamos hablando de una enfermedad de carácter claramente estacional.

La enfermedad afecta a los pulmones, bronquios, garganta, nariz, oídos, y puede complicarse con cuadros de asma y dolores articulares. Los síntomas más habituales son fiebre, escalofríos, dolor muscular y en las articulaciones, dolor de cabeza, tos, congestión nasal, malestar de garganta, cansancio y debilidad.

La gripe puede llegar a ser una enfermedad seria. Generalmente se resuelve con cierta medicación y/o unos días en cama pero existen grupos de personas (mayores de 65 años, personas con enfermedades crónicas como la diabetes, el asma, el virus del sida, enfermedades cardiacas...) que pueden encontrarse con dificultades para recuperarse de la misma.

A finales del siglo XIX más de 20 millones de personas murieron de gripe en el mundo. La epidemia de 1917 dejo más víctimas mortales que la Primera Guerra Mundial. En 1968, la ola de gripe que azotó Hong Kong se cobró unas 700.000 vidas ${ }^{1}$.

Cada año, millones de personas contraen gripe en el mundo y muchas requieren ser hospitalizadas. Para el doctor Steven Mostow, de la Universidad de Colorado, la influenza y sus complicaciones pueden provocar una verdadera catástrofe y así lo expresó en unas declaraciones a la CNN Internacional donde declaró: «nos preocupa mucho que se extienda en todo el mundo una pandemia de gripe que podría afectar a un $40 \%$ de la población mundial».

La evolución de los medios de transporte y el incremento de la movilidad favorece en gran medida la difusión de este tipo de enfermedades. En este sentido personal investigador de la O.M.S. y del Centro para el Control y Prevención de Enfermedades de Estados Unidos siguen de cerca los movimientos y las mutaciones de cada epidemia de gripe dado que las consecuencias de una epidemia mundial podrían tener efectos catastróficos.

Durante el mes de enero del año 2000 han sido muchos los titulares relacionados con la gripe. Tal como recogía un artículo publicado en el diario el Mundo el 10 de Enero de 2000 «la gripe alcanza niveles de epidemia en el Reino Unido y ha colocado en situación de crisis al sistema de seguridad social y a los hospitales del país». Al mismo tiempo, en Italia, las autoridades daban la voz de alarma dado que las llamadas a los servicios de ambulancias eran masivas y muchos servicios de urgencia estaban colapsados.

1 Infosel. S.A. http://www.terra.com.mx/noticias/nota/20000119/091030.htm 
De igual modo existen ejemplos de situaciones similares en nuestro país tal como muestra CERES TV en uno de sus titulares de fecha 20 de enero de 2000, «La gripe colapsa el Servicio de Urgencias del Hospital Nuestra Señora de Sonsoles de Ávila». En la epidemia del año 1998 se detectaron un total de 128.626 casos de gripe en la C.A.P.V. ${ }^{2}$.

En definitiva las epidemias de gripe tienen unos impactos directos sobre los sistemas sanitarios que, en muchas ocasiones se ven superados por el número de casos, no pudiendo atender correctamente a todos ellos.

La resolución de este tipo de problemáticas, de carácter estacional, puede ser de dos tipos:

A) Reactivas: Aquellas que pasan por ampliaciones temporales de los recursos sanitarios con el fin de atender a la demanda en picos puntuales del número de casos.

B) Proactivas: Son aquellas medidas basadas en una mejora planificación a partir de la elaboración de estimaciones de los casos gripales que se esperan y de la aceleración de los procesos de investigación que permiten la identificación del tipo de virus en cada caso y la creación ágil de sus correspondientes vacunas. Es aquí donde cobra sentido cualquier tipo de investigación que pueda servir de apoyo para este fin. Es en esta área de trabajo donde se centra el estudio que a continuación se presenta.

Si fuera posible estimar, con cierta fiabilidad, el número de casos de gripe que se van a registrar en un plazo breve de tiempo (por ejemplo dentro de una semana) resultaría mucho más fácil y eficaz la gestión de los recursos sanitarios disponibles.

\section{Objetivos, datos y metodología}

Los factores que se deben considerar en el estudio de las epidemias gripales son múltiples y complejos. Además de los elementos propios de la microbiología (análisis viral, caracterizaciones microscópicas...) resulta necesario considerar también tanto factores relacionados con la difusión de procesos en el espacio (contagios) como elementos de carácter ambiental (temperatura, situaciones sinópticas, humedad, contaminación...). Todo ello hace que nos enfrentemos a un problema complejo que requerirá respuestas complejas para poder ser resuelto.

Sería excesivamente ambicioso querer dar respuestas a cada uno de estos campos señalados, por lo que, se ha optado en una primera fase, por buscar algún tipo de relación entre el número de casos de gripe que se han registrado semanalmente en el Territorio Histórico de Alava, fundamentalmente en la ciudad de Vitoria, desde la semana número 44 a la semana 52 del año 1999 (correspondientes con los meses de noviembre y diciembre) y algunas variables climático-ambientales como la temperatura y los tipos de circulación atmosférica predominantes, dejando para un posterior trabajo la elaboración de un estudio de difusión espacial de la gripe en la Comunidad Autónoma del País Vasco.

2 Datos provisionales correspondientes al periodo 1 de Enero 7 de Noviembre de 1998 en la Comunidad Autónoma del País Vasco.

Investigaciones Geográficas, $n^{\circ} 26(2001)$ 


\subsection{Las fuentes de datos}

Las fuentes de datos empleadas para la elaboración de este estudio han sido:

- Por un lado, los valores diezminutarios de temperatura registrados, en décimas de grado, por la Estación E040, situada en Vitoria, perteneciente a la Red Automática de Estaciones Meteorológica gestionada por el Servicio Vasco de Meteorología de Gobierno Vasco.

- Por otro, en relación con la información referente a los casos de gripe, la fuente básica ha sido la Red de Médicos Vigías de la CAPV. Una red de médicos vigías compuesta por médicos, pediatras y personal sanitario de atención primaria. Cada año participa en la red más de 100 profesionales de atención primaria de los tres territorios de la CAPV. El método de selección del número de integrantes en la red se realiza de forma proporcional ajustándose en función de la estructura de edad de la población atendida y la población de referencia. Mencionada red ha suministrado información en relación con los casos de gripe registrados desde la semana 40 de 1999 hasta la 20 de 2000 para cada Territorio Histórico. También se aporta la tasa de gripe por semana y Territorio Histórico. El cálculo de esta tasa se corresponde con la razón entre los casos registrados y la población de referencia de cada médico vigía, por cada 100.000 habitantes.

- En tercer lugar se han empleado los Mapas de Análisis en Superficie a las 12 horas (TMG) que publica el Instituto Nacional de Meteorología en su Boletín Diario y la clasificación de tipos de circulación definidos por Jekinson, A. en 1977 adaptada a la peninsula con el fin de obtener un tipo de circulación diario para los meses de noviembre y diciembre del año 1999.

\subsection{Definición de Criterios}

Dado el carácter de «pre-test» de este estudio se ha optado por considerar exclusivamente los meses de noviembre y diciembre para el Territorio Histórico de Álava. Las razones básicas se encuentran en que durante este periodo los casos de gripe ascienden, de forma más o menos continua, hasta alcanzar su pico máximo en Álava a finales del año 1999, comenzando el número de casos un descenso progresivo a partir de la primera semana del año 2000 como muestra el Gráfico 1 que a continuación se presenta.

En segundo término se ha seleccionado la semana epidemiológica ${ }^{3}$ como unidad temporal de análisis dado que la notificación de la información registrada por la Red de Médicos Vigías de Gripe de la C.A.P.V. al centro coordinador se realiza cada siete días. Es por ello por lo que se han adaptado el tratamiento de los datos meteorológicos a esta frecuencia temporal ya definida.

Un tercer criterio ha consistido en la selección del Territorio Histórico de Alava como ámbito de aplicación del análisis. Está selección está motivada por ser Vitoria el núcleo de población más representativo, en cuanto al número de habitantes, de todo el Territorio Histórico de Álava, con un eminente carácter macrocefálico con respecto al resto del Territo-

3 Semana 40 de 1999 (Se inició el 3 de Octubre de 1999). Semana 20 de 2000 (Finalizó el 20 de Mayo de 2000). 
Gráfico 1

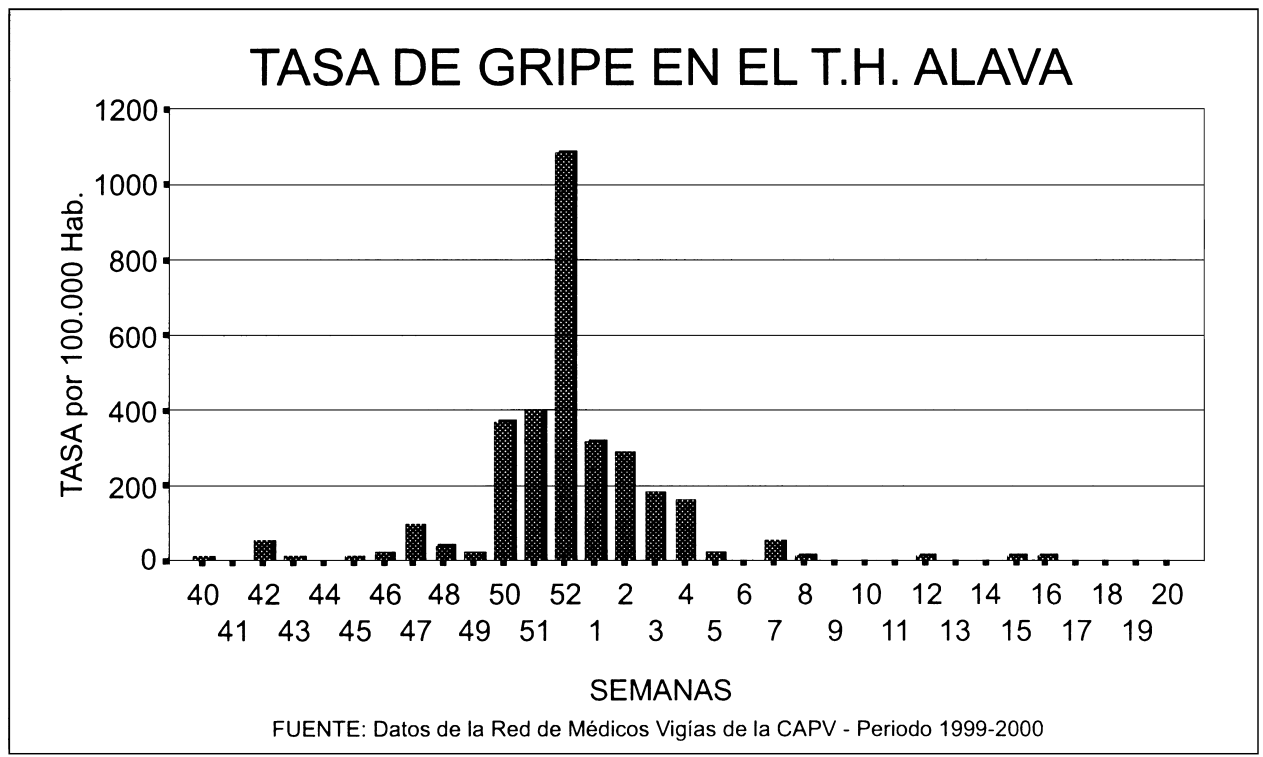

rio. Detrás de esta elección se encuentra la necesidad de focalizar los datos obtenidos en un punto territorial lo más concreto posible.

\subsection{Metodología}

El método aplicado ha sido simple. Se ha buscado la existencia de algún tipo de relación entre la variabilidad térmica y el número de infecciones por virus de gripe que se registran por la Red de Vigilancia Epidemiológica del Servicio Vasco de Salud, a partir de una doble hipótesis de trabajo.

La primera hipótesis es planteada a partir del supuesto de que las infecciones de gripe que se producen una semana, son detectadas y diagnosticadas por la Red de Vigilancia Epidemiológica esa misma semana.

La segunda hipótesis, por el contrario, se plantea a partir de la existencia de un retardo medio de siete días entre la fecha en que se produce la infección del individuo y el dictado del diagnóstico médico.

En cada una de las hipótesis anteriores se han definido dos escenarios térmicos. El primero de ellos de ha definido a partir de los 1.008 datos diezminutarios que se corresponden con una semana. El segundo, ha sido consecuencia de restringir el número de datos térmicos empleados a, exclusivamente, aquellos datos diarios registrados entre las 8:00 horas y las 22:50 horas, ambas tomas incluidas.

En los dos tipos de escenarios planteados se han obtenido los valores máximos y los mínimos de la temperatura así como su amplitud térmica, sus valores medios y su desviación estándar, además de los Coeficientes de Variación de la temperatura para cada una de las semanas definidas en la Tabla 1. 
Tabla 1

PERIODOS TEMPORALES ANALIZADOS

\begin{tabular}{|c|c|c|}
\hline Semana & Del día & Al día \\
\hline $\mathbf{4 4}$ & 1 de Noviembre & 7 de Noviembre \\
$\mathbf{4 5}$ & 8 de Noviembre & 14 de Noviembre \\
$\mathbf{4 6}$ & 15 de Noviembre & 21 de Noviembre \\
$\mathbf{4 7}$ & 22 de Noviembre & 28 de Noviembre \\
$\mathbf{4 8}$ & 29 de Noviembre & 5 de Diciembre \\
$\mathbf{4 9}$ & 6 de Diciembre & 12 de Diciembre \\
$\mathbf{5 0}$ & 13 de Diciembre & 19 de Diciembre \\
$\mathbf{5 1}$ & 20 de Diciembre & 26 de Diciembre \\
$\mathbf{5 2}$ & 27 de Diciembre & 31 de Diciembre \\
\hline
\end{tabular}

ESQUEMA METODOLÓGICO

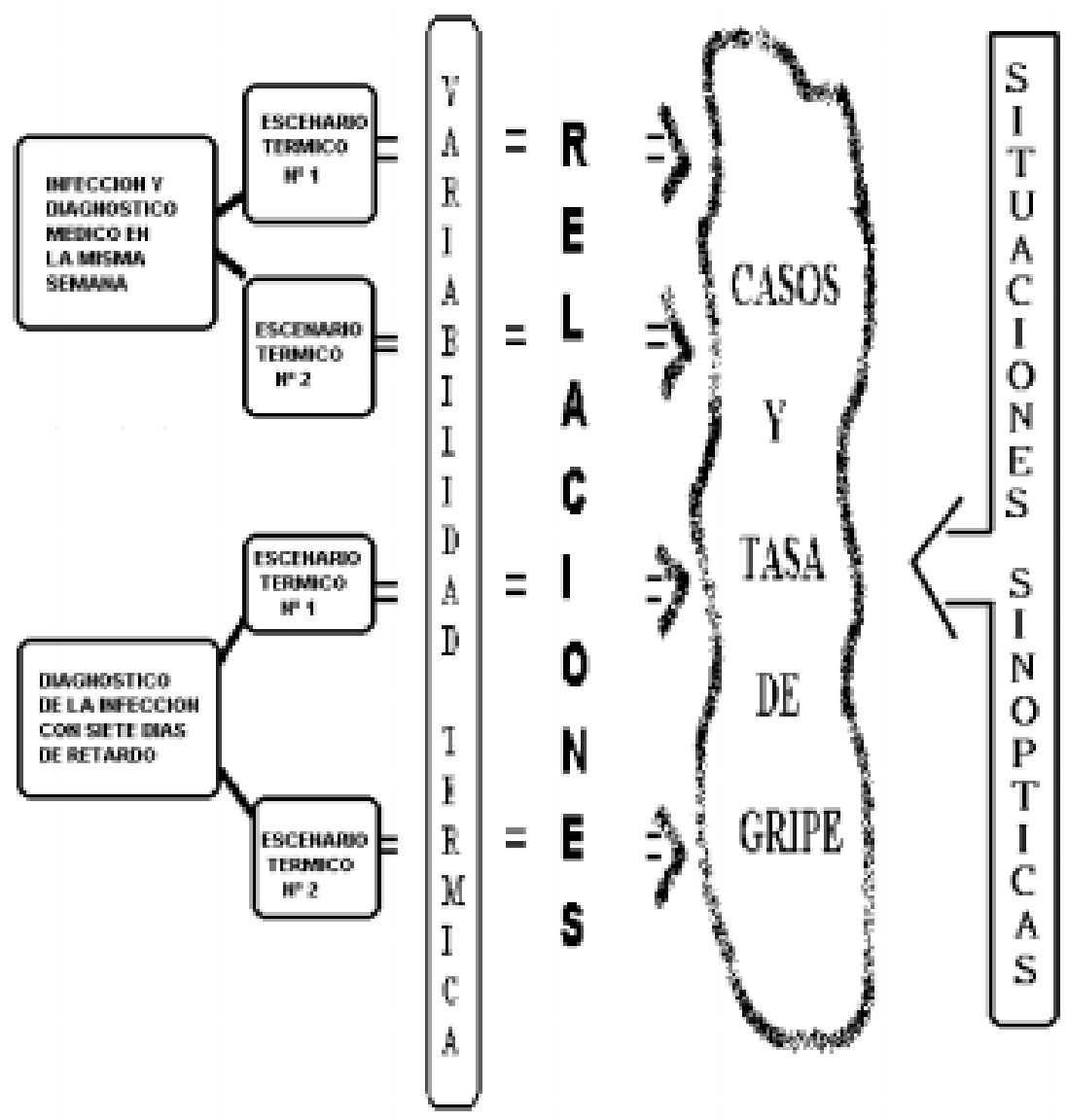


En relación con la vertiente epidemiológica del estudio se han extraído los datos referentes al Número de Casos de gripe registrados en Álava durante las semanas mencionadas en la Tabla 1 así como la Tasa de Gripe ${ }^{4}$ por cada cien mil habitantes.

En la segunda hipótesis ha sido necesaria la utilización del Número de Casos y la Tasa de Gripe detectados en la semana 1 del año 2000 dado el desplazamiento semanal señalado con anterioridad.

Seguidamente se han aplicado diferentes análisis estadísticos bivariantes (Coeficientes de Correlación de Pearson, Kendall y Spearman) para cada uno de las hipótesis planteadas y los escenarios definidos para incidir con posterioridad en la interpretación de aquellos resultados más significativos.

Por último, se han puesto en relación la frecuencia semanal de las situaciones sinópticas y los tipos de circulación registrados (Jenkinson, 1977) con la evolución semanal experimentada por los episodios epidémicos.

\section{Presentación de resultados}

\subsection{Gripe y variabilidad térmica}

En primer lugar se muestran los resultados correspondientes a la hipótesis en que las infecciones y los diagnósticos se producen en la misma semana. El Gráfico 2 recoge esta situación para el total de los datos térmicos mientras que el Gráfico 3 representa exclusivamente las temperaturas diurnas.

La curva de casos es semejante en los dos escenarios. Lo que varía levemente, entre ambos gráficos, es la línea que representa la dispersión semanal que experimenta las temperaturas.

En una primera lectura del Gráfico 2 resulta posible constatar un ligero y progresivo aumento de los valores en función del tiempo, principalmente del número de casos de gripe según se acerca el final del año.

De igual modo, desde un punto de vista global, la desviación de las temperaturas con respecto a sus valores medios semanales también experimenta un progresivo aumento, reflejando este hecho una mayor dispersión de las temperaturas en las semanas del mes de Diciembre.

Con respecto al Gráfico 3 podemos destacar el hecho de que, a pesar de tener la impresión visual de que hay una mayor variación de la dispersión de los valores térmicos diurnos, el umbral en que se sitúan estos valores de temperatura es menor que en el escenario previo.

Podemos señalar dos hechos aislados que resultan significativos. En la semana 45 es apreciable un descenso brusco de la dispersión de las temperaturas en ambos escenarios (Gráfico 2) (Gráfico 3). Se trata de la semana en que ya se constata la presencia del virus gripal entre la población al elaborarse el primer diagnóstico positivo de frotis faríngeo infectado por el virus de la gripe en la ciudad de Vitoria.

Resulta igualmente curioso el hecho de que encontremos un descenso significativo del número de diagnósticos en la semana 49 (del 6 al 12 de Diciembre). No parece desa-

4 Tasa por 100.000 habitantes $=($ casos registrados $/$ población de referencia $) \times 100.000$. 
Gráfico 2

HIPÓTESIS 1 - ESCENARIO 1

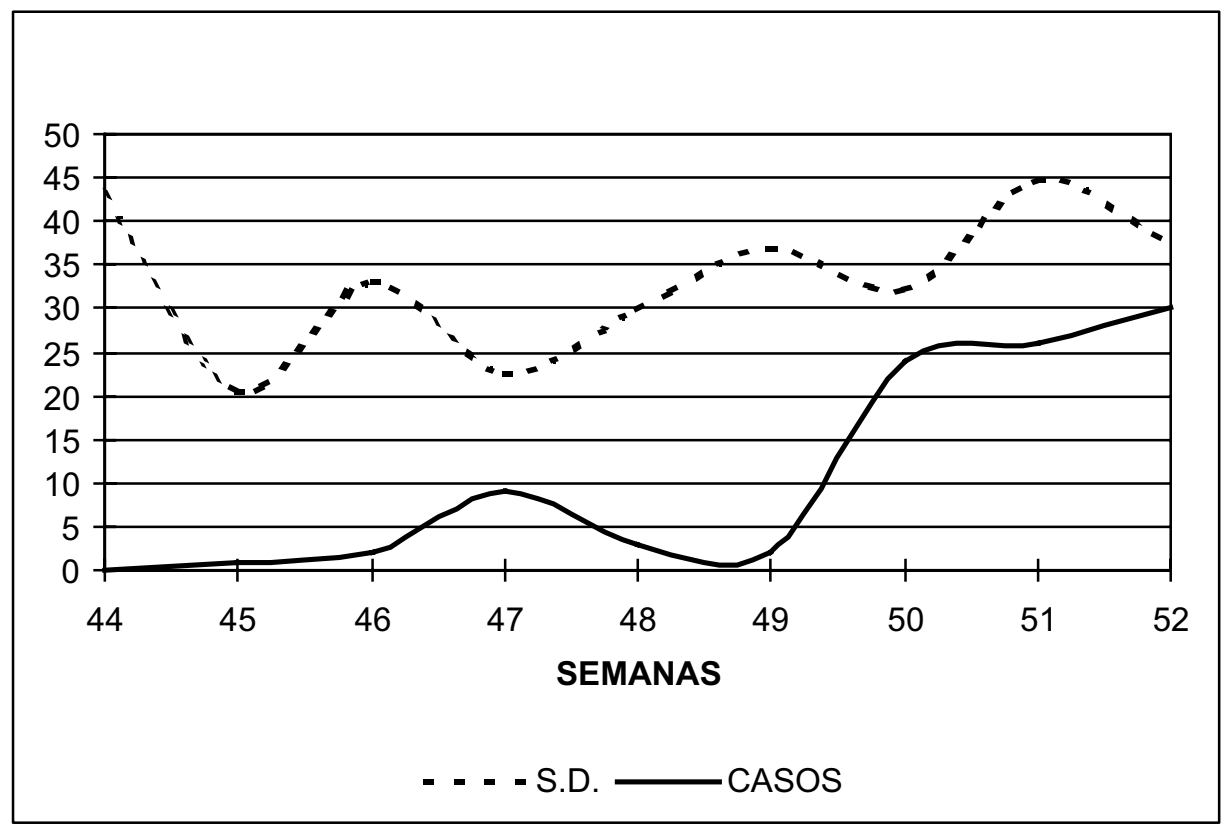

Gráfico 3

HIPÓTESIS 1 - ESCENARIO 2

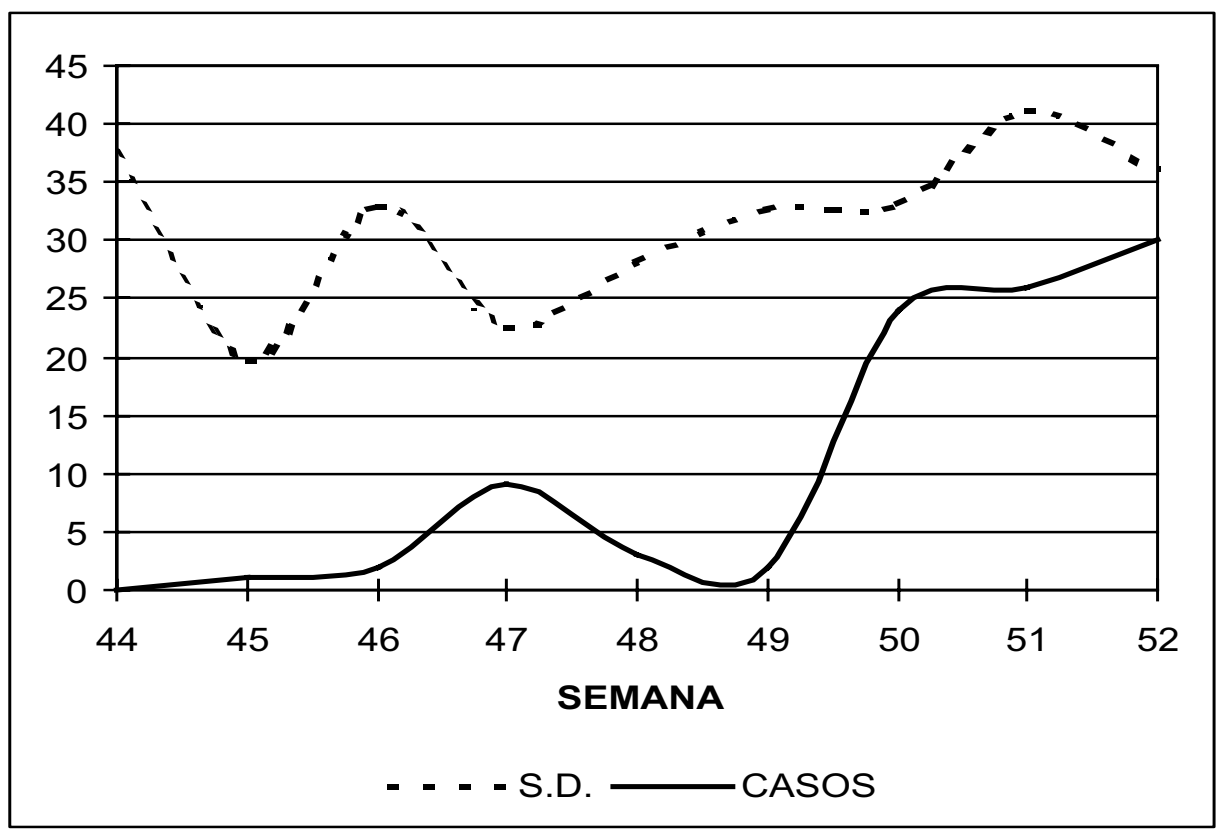


certado señalar que mencionada semana estuvo marcada por la existencia de dos días festivos que originaron el conocido puente vacacional del mes de Diciembre. Ello parece incidir claramente en que el número de diagnósticos descienda durante esta semana. Se trata de un hecho curioso que bien pudiera ser analizado desde un punto de vista sociológico.

En ambos escenarios parece existir, en un análisis visual, una dinámica de comportamiento inverso entre ambos factores, coincidiendo un aumento del número de casos diagnosticados con una bajada en la dispersión de los valores térmicos y viceversa. Un claro ejemplo de esto viene representado en la semana 47, en la 49 y la 50. En menor medida se percibe este hecho también en la semana 51.

En un intento por plasmar de forma numérica esta aparente coincidencia visual se han estimado los Coeficientes de Correlación entre distintos indicadores térmicos como la amplitud térmica (AMPLI), las temperaturas máximas, mínimas y medias (T_MAX, T_MIN, T_MED), la desviación estándar (SD), la variabilidad (CV) y los indicadores epidemiológicos disponibles como el número de casos y la tasa de gripe registrados (CASOS), (TASA).

Los resultados obtenidos nos alejan de nuestra primera interpretación constatándose cierta relación exclusivamente entre las temperaturas mínimas registradas y la tasa de gripe o entre la dispersión de los valores diezminutarios y el número de casos del primer escenario.

PRIMERA HIPÓTESIS (DIAGNÓSTICO EN SEMANA DE INFECCIÓN) ESCENARIO TÉRMICO 1 (TODOS LOS DATOS DE T $T^{a}$ )

COEF. CORREL. PEARSON

\begin{tabular}{|c|c|c|c|c|c|c|}
\hline & AMPLI & CV & T_MAX & T_MED & T_MIN & SD \\
\hline CASOS &, 1961 &, 3624 &, 3622 &, 0056 &, 2570 &, 4068 \\
\hline TASA &, 1473 &, 2358 &, 3282 &, 0449 &, 4032 &, 3543 \\
\hline
\end{tabular}

PRIMERA HIPÓTESIS (DIAGNÓSTICO EN SEMANA DE INFECCIÓN) ESCENARIO TÉRMICO 2 (SÓLO DATOS DIURNOS DE T ${ }^{a}$ )

COEF. CORREL. PEARSON

\begin{tabular}{|c|c|c|c|c|c|c|}
\hline & AMPLI & CV & T_MAX & T_MED & T_MIN & SD \\
\hline CASOS &, 2612 &, 2818 &, 3010 &, 0143 &, 0833 &, 0809 \\
\hline TASA &, 2279 &, 1825 &, 3113 &, 0451 &, 2597 &, 0814 \\
\hline
\end{tabular}


Donde sí se ha detectado una mayor relación entre los indicadores térmicos definidos y el Número de Casos o la Tasa de Gripe ha sido con nuestra segunda hipótesis de trabajo (aplicando un retardo semanal entre la infección y el diagnóstico) donde se han alcanzado Coeficientes de Correlación mucho más significativos con valores de $r=0,547$ entre la desviación típica de la temperatura y número de casos de gripe diagnosticados, de $\mathrm{r}=0,604$ entre la desviación típica de la temperatura y tasa de gripe y valores de correlación de $r=0,623$ entre la desviación típica y número de casos de $r=0,452$ entre la desviación típica y tasa de gripe.

\section{SEGUNDA HIPÓTESIS (DATOS GRIPE DESPLAZADOS) \\ ESCENARIO 1 (TODOS LOS DATOS) \\ COEF. CORREL. PEARSON}

\begin{tabular}{|c|c|c|c|c|c|c|}
\hline & AMPLI & CV & MAX & MED & MIN & SD \\
\hline CASOS &, 3142 &, 5404 &, 3144 &, 0046 &, 3273 &, 5478 \\
\hline TASA &, 4256 &, 2519 &, 3360 &, 2131 &, 3279 &, 6042 \\
\hline
\end{tabular}

\section{SEGUNDA HIPÓTESIS (DATOS GRIPE DESPLAZADOS) ESCENARIO 2 (DATOS DIURNOS) \\ COEF. CORREL. PEARSON}

\begin{tabular}{|c|c|c|c|c|c|c|}
\hline & AMPLI & CV & MAX & MED & MIN & SD \\
\hline CASOS &, 3512 &, 4334 &, 1826 &, 0069 &, 4874 &, 6231 \\
\hline TASA &, 4638 &, 1336 &, 2942 &, 2320 &, 4723 &, 4524 \\
\hline
\end{tabular}

Parece ser que el estadístico de la Desviación Estándar y el Coeficiente de Variación son los parámetros que mejor relación tiene con el proceso de expansión experimentado por el virus de la gripe entre la semana 44 y la 52 del año 1999, en la ciudad de Vitoria. En los siguientes gráficos, correspondientes a la segunda hipótesis en sus dos escenarios térmicos, se muestra la evolución temporal de los casos de gripe desplazados una semana junto a los valores de la desviación típica de las temperaturas.

Resulta significativo, bajo esta segunda hipótesis de trabajo, el hecho de que al aplicar un desplazamiento temporal de 7 días, las curvas se reajusten de forma importante. Parece apropiado deducir que el paralelismo aumentaría si se aplicara en el análisis un retardo semejante al periodo de incubación del virus con un margen, por exceso y por defecto.

Desde el punto de vista de la climatología médica podemos entender que el entorno atmosférico en el que se desarrolla la actividad humana y principalmente la variaciones de alta frecuencia de la temperatura, que no son claramente perceptibles por las personas, facilitan la difusión del virus de la gripe bien porque estas condiciones microclimáticas esti- 
Gráfico 4

HIPÓTESIS 2 - ESCENARIO 1

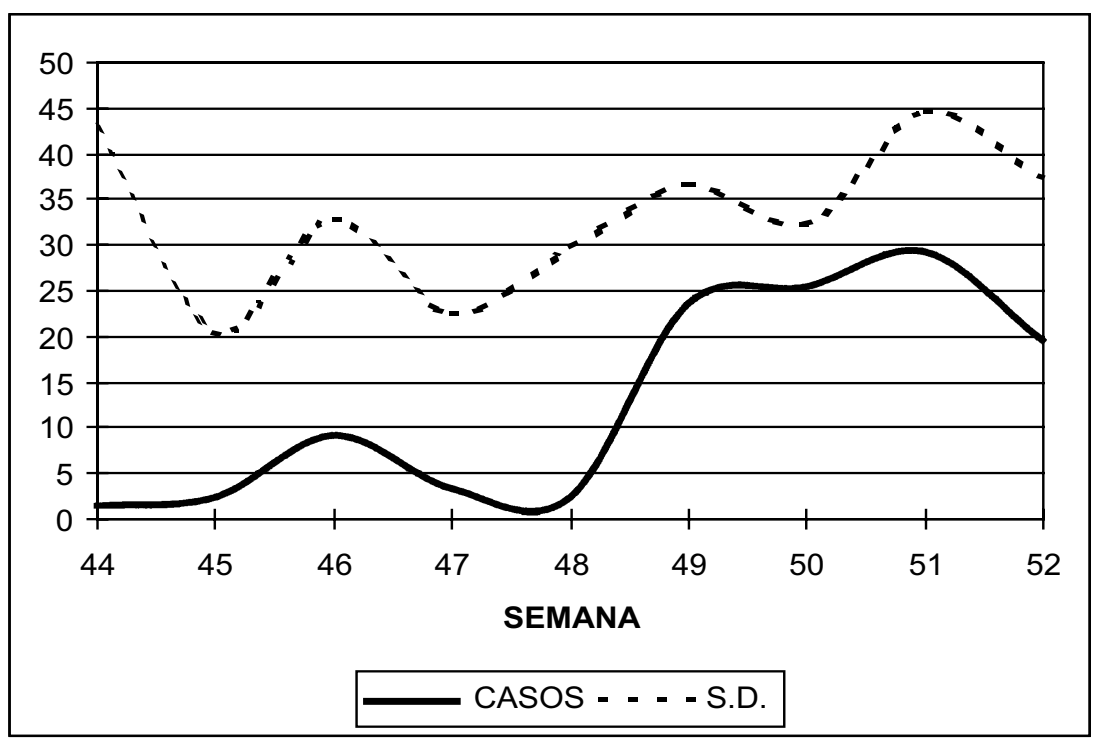

Gráfico 5

HIPÓTESIS 2 - ESCENARIO 2

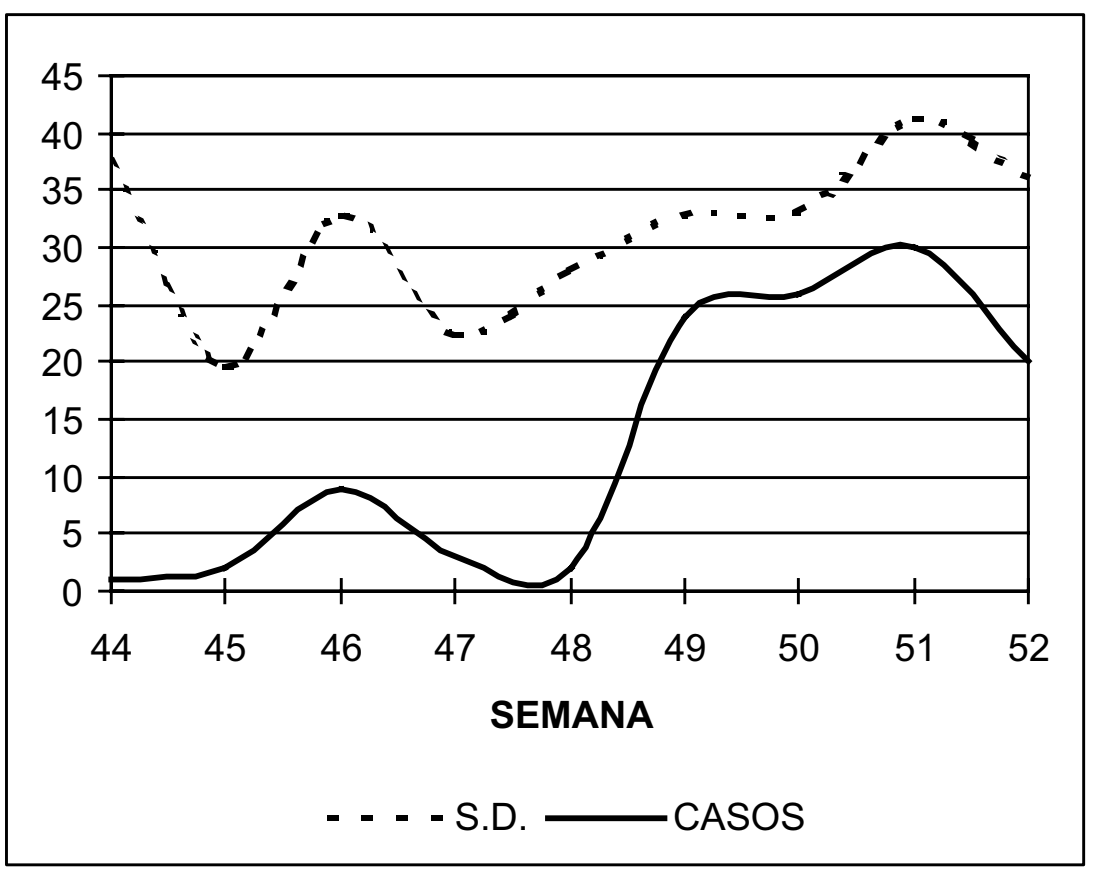


mulan la expansión del microorganismo, bien porque los contrastes térmicos incrementan la receptividad del virus por parte de las personas.

\subsection{Gripe y tipos de circulación atmosférica}

El comportamiento térmico de una región suele encontrarse relacionado, de forma más o menos directa, con las situaciones sinópticas que se registran en su entorno y consecuentemente con los tipos de circulación dominantes.

Los tipos de circulación definidos se corresponde con una situación global peninsular y pueden, en algunos casos, no representar la situación específica de la ciudad de Vitoria. La tipología definida diferencia entre Tipo A (Anticiclónico), N (Norte), E (Este), S (Sur), NW (Noroeste), C (Ciclónico), NE (Noreste), SE (Sureste), SW (Suroeste), W (Oeste).

El hecho de que puedan darse varios tipos de circulación en una misma semana representa un problema añadido. Para solucionar esta circunstancia se han analizado las situaciones sinópticas semanales en función de los siguientes tres factores:

- La variedad o diversidad semanal de tipos de circulación. La diversidad debe ser entendida como el número de tipos que se registran esa semana.

- El número de rupturas que se producen en la secuencia semanal. Indica el número de veces que hay cambio del tipo de circulación diario.

- La brusquedad de las rupturas entre tipos. Se ha concretado mediante las unidades de ángulos de $45^{\mathrm{a}}$ que se recorren al pasar de un tipo de circulación a otro diferente en una rosa de los vientos.

La representación gráfica de estos datos facilita la interpretación de los mismos.

Parece quedar demostrado que las rupturas en general y la brusquedad de las mismas en particular tienen un especial significado e impacto sobre el comportamiento del virus en el segundo supuesto (Gráfico 7).

De este modo en la semana 46 se produce 6 rupturas o cambios en la dinámica atmosférica con tipos de circulación del E del NE y del NW. Estos cambios además son considerados como muy bruscos por la disposición que los tipos toman a lo largo de la semana. En esas circunstancias la tasa de gripe se dispara, en términos relativos, hasta un 96,4 por cien mil para volver a descender posteriormente.

Bajo esta segunda hipótesis vuelve a producirse un nuevo incremento de las rupturas y de su brusquedad entre la semana 49 y la 51 coincidiendo con una verdadera eclosión continuada del número de frotis faríngeos analizados con resultado positivo. Los tipos de circulación predominantes en este periodo fueron básicamente rachas anticilónicas salteadas por tipos del NW y del NE.

\section{Conclusiones}

Los resultados obtenidos se consideran relevantes. A pesar de no existir correlaciones realmente importantes entre las temperaturas medias y el número de casos, si se dan coincidencias significativas entre las desviaciones típicas que experimentan las temperaturas, su variabilidad y el número de casos de gripe que se han registrado sobre todo bajo el segundo supuesto donde se asume que la infección se produce una semana antes del diagnóstico médico. 


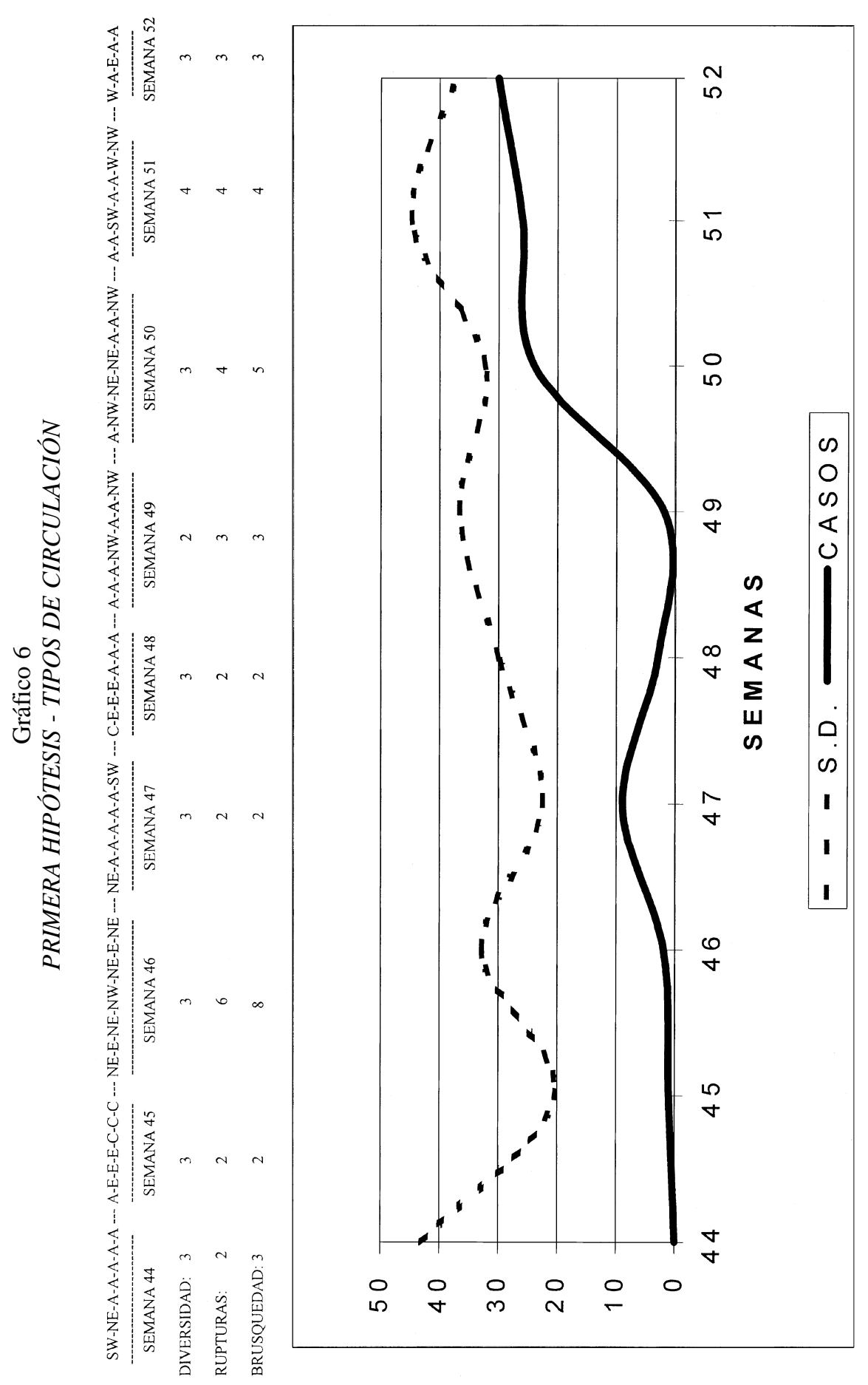

Investigaciones Geográficas, $n^{\circ} 26(2001)$ 


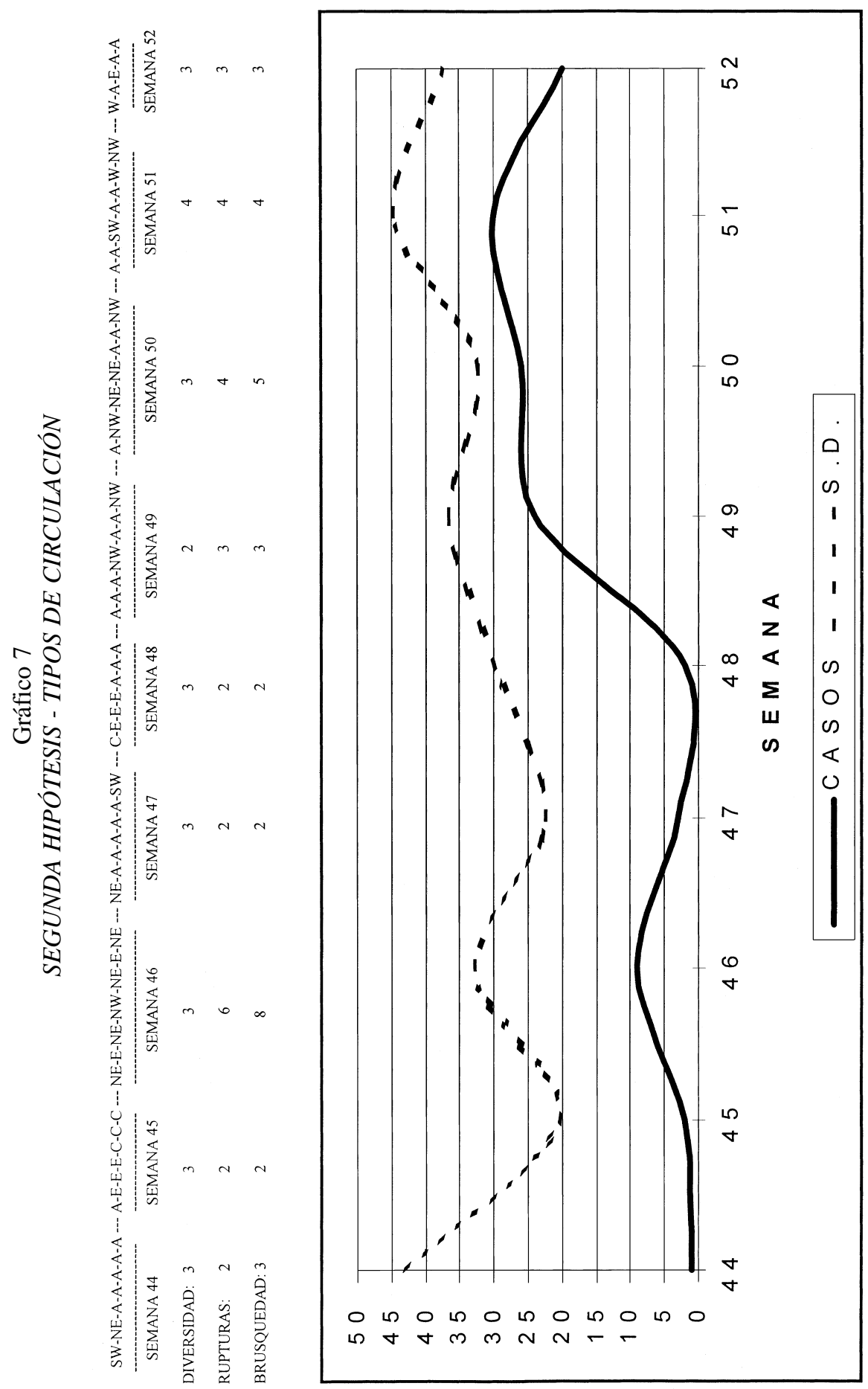


Se cree posible mejorar los niveles de correlación encontrados alterando los retardos aplicados (4, 5, 6, días) en función del virus gripal que se tenga y su periodo medio de incubación. De igual modo, sería significativo poder desarrollar un análisis de regresión múltiple incluyendo otras variables meteorológicas como la humedad relativa, la presión atmosférica y los niveles de contaminación.

Con respecto a la influencia de los tipos de circulación parece apropiado señalar que la inestabilidad atmosférica favorece la expansión del virus. La mayor o menor frecuencia en la alternancia de los tipos de circulación y sobre todo la brusquedad de esa alternancia condicionan la difusión del número de casos de gripe para la segunda hipótesis planteada en este estudio.

Dada la complejidad multivariante del tema objeto de análisis podemos considerar los resultados satisfactorios dado que insinúan la existencia clara de una relación entre las condiciones ambientales, en este caso térmicas y de circulación atmosférica, y la expansión de las infecciones por el virus gripal.

Si realizamos una lectura inversa de la existencia de las coincidencias expuestas se puede indicar, en función de la variabilidad experimentada por las temperaturas y de los tipos de circulación habidos durante una semana, un número de casos de gripe para la semana siguiente, siempre que nos ajustemos a la situación contextual definida de una fase de expansión del número de casos. Sin tener que ser realmente exacto, si puede convertirse en un método más de análisis dentro de la vertiente ambiental del estudio de la gripe.

\section{Referencias bibliográficas}

ARTEAGOITIA, J.M., (2000): «Vigilancia Epidemiológica. Red de Médicos Vigías de la Comunidad Autónoma del País Vasco» Congreso Salud y Trabajo: prevención integrada. Bilbao 6 y 7 de Abril de 2000. Dirección de Salud Pública. Departamento de Sanidad. Gobierno Vasco.

BOLETÍN EPIDEMIOLÓGICO DE LA COMUNIDAD AUTÓNOMA DEL PAÍS VASCO. Núm. 4 -Trimestre 4 Año 1998 «Enfermedades de declaración obligatoria. Datos correspondientes a las semanas 1-44 de 1998».

BOLETÍN METEOROLÓGICO, (1999): Ministerio de Medio Ambiente. Instituto Nacional de Meteorología. Núm. 305 a 365.

BULLEN, N., MOON G., JONES, K. (1996): «Defining localities for health planning: a GIS approach». Soc. Sci. Med. Num. 42 Pages. 801-816.

GESLER, W. (1986): «The uses of spatial analysis in medical geography: a rewiew». Social Science \& Medicine. Num. 23. Pages. 963-973.

JENKINSON, A.F. COLLISON, P. (1977): «An initial climatology of Gales over thr North Sea» Sinoptic Climatology Branch.

Memprandum $\mathrm{N}^{\mathrm{o}}$ 62, Meteorological Office. London, $18 \mathrm{pp}$.

SALAZAR, A. et al. (1999):«Sistema de Información Geográfica en salud pública. Una herramienta para la vigilancia». Boletín epidemiológico semanal. Ministerio de Sanidad y Consumo. Proyecto financiado por el Institut Valenciá d'estudis en Salut Pública: $N^{\circ}$ 004/19998 y 001/1999.

RUIZ URRESTARAZU, E. (1982): La transición climática del Cantábrico oriental al valle medio del Ebro. (Tesis Doctoral) Editores: Diputación Foral de Álava. Vitoria-Gasteiz 


\section{Páginas WEB}

http://www.terra.com.mx/noticias/nota/20000119/091030.htm

http://www.diariomedico.com

http://www.intergaleno.com/prevencion/p-gripe.htm

http://www.montefiorecentral.com/webfinal/niños/influegripa.htm

http://dgsp.san.gva.es/SSCC/Epidemiologia/Centinelas/gripe/evol9798.htm 